\title{
Atlanto-axial subluxation in rheumatoid arthritis
}

\section{A 5-year follow-up study}

\author{
J. A. MATHEWS \\ From the Department of Rheumatology, St. Thomas's Hospital, London SE1 7EH
}

In 1969 the results of a survey of atlanto-axial subluxation in all seventy-six consecutive rheumatoid patients attending a clinic were published (Mathews, 1969). Abnormal separation of the odontoid process from the anterior arch of the atlas was found in nineteen $(25 \%)$ patients and was found to be more common in patients with more serious forms of the disease. In addition, an abnormal vertical relationship of the tip of the odontoid process to the base of the skull was found in six $(8 \%)$ patients. A curious discrepancy between the amount of subluxation and the presence of neurological damage led to the supposition that this finding could often be relatively innocuous and indicated the need for a follow-up study to clarify the natural history of rheumatoid disease in this region.

\section{Material}

Originally patients were included if they satisfied the A.R.A. criteria for definite rheumatoid arthritis, and seventy of the 76 patients had at least one additional diagnostic feature. To establish the technique and its normal values, 28 control subjects matched for age and sex were also examined. After 5 years an attempt was made to review all patients. Fifty-four $(74 \%)$ were found and re-examined radiologically and all but one of these clinically. Sixteen patients $(21 \%)$ had died, but in no case was this thought to be related to cervical disease, and six patients $(8 \%)$ were lost to follow-up, including one who was examined clinically but declined to wait for radiological examination.

Fig. 1 shows the percentage of patients with each amount of anteroposterior atlanto-axial separation in the original study and the percentage follow-up achieved. It shows that the $22(29 \%)$ patients lost were not concentrated into any particular group. The mean duration of follow-up was 5 years 5 months, the range being 4 years 7 months to 6 years 1 month.

\section{Method}

This was identical to that of the original study. All patients were again questioned about cervical and neurological symptoms, the cervical spine and nervous system were

Accepted for publication May 2, 1974.

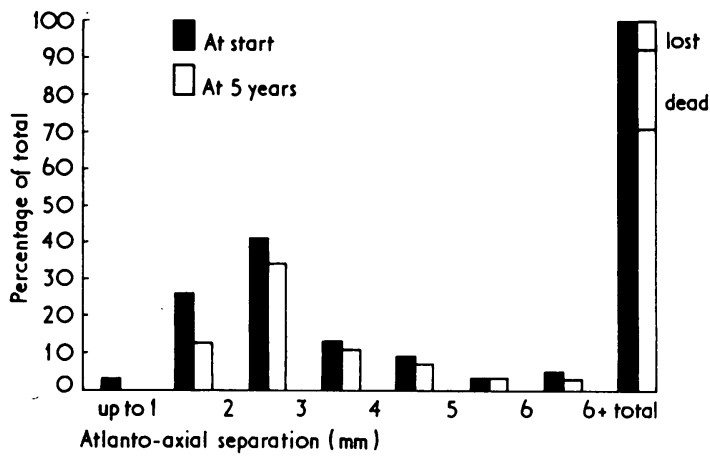

FIG. 1 The total follow-up is shown with the percentage achieved in each category of atlanto-axial separation

examined, and a midline lateral tomogram taken centred on the odontoid process with the upper cervical spine in full active flexion. The midline films were again traced and measurements compared with those at the start of the study. In practice it was found that errors could be minimized and more accurate assessment of change made by direct comparison of the films and direct measurement. By this technique changes of $1 \mathrm{~mm}$ or more were thought to be significant.

\section{Results}

ANTEROPOSTERIOR SUBLUXATION

Alteration in the atlanto-axial separation is recorded in Fig. 2. The gap increased in nine patients by the following amounts: $1 \mathrm{~mm}$ in $5 ; 2.5 \mathrm{~mm}$ in $2 ; 3 \mathrm{~mm}$ and $4 \mathrm{~mm}$ in 1 each. Fig. 3 illustrates an increase of $2.5 \mathrm{~mm}$. 'Clunking', the 'palate sign', and 'abnormal laxity' are all clinical signs thought to be specific for anteroposterior instability. They were again found to be unreliable, only one sign being positive in each of three patients. Thirty-eight patients had no alteration in the separation and seven actually showed a decrease. It can be seen from Fig. 2 that whereas the patients with increased or unchanged measurements are scattered throughout the groups of original measurements, those with decreased separation all started the study with substantial subluxation. 


\begin{tabular}{|c|c|c|c|c|c|c|c|c|c|}
\hline Original meas & nent $(m m)$ : up to & 1 & 2 & 3 & 4 & 5 & 6 & $6+$ & total \\
\hline Alterotion & increase & 0 & $\bullet \bullet$ & & ০ & 0 & 0 & 0 & 9 \\
\hline in 5 & unchanged & 0 & 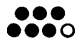 & & $\bullet \bullet ०$ & $\bullet \bullet \bullet$ & $\bullet$ & $\circ$ & 38 \\
\hline years & decreose & 0 & 0 & 0 & ০০০ & ০० & 0 & $\bullet$ & \\
\hline & Total & 0 & 10 & 26 & 8 & 5 & 2 & 3 & \\
\hline
\end{tabular}

FIG. 2 Alteration in atlanto-axial separation over the period of study. All patients are represented by $\bullet$ except where vertical shift has occurred $\bigcirc$. Measurements are in $\mathrm{mm}$

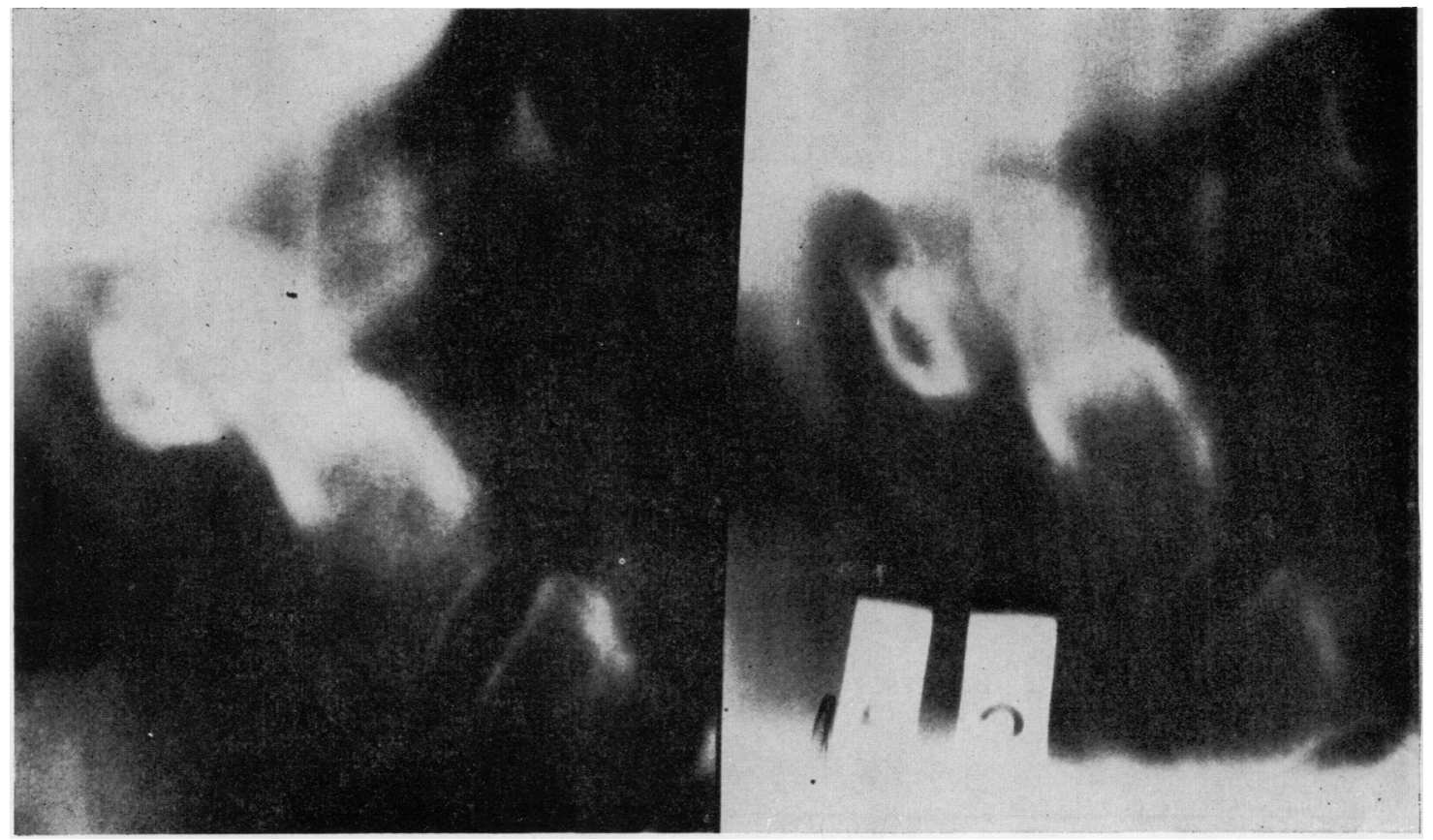

FIG. 3 This shows an increase in anteroposterior separation from 2.5 to $5.0 \mathrm{~mm}$. There is no vertical shift

VERTICAL SUBLUXATION

Apparent vertical shifting of the odontoid process (really a descent of skull and atlas) actually occurred more often than anteroposterior subluxation and was found in eighteen patients (Table I). This group can be seen from Fig. 2 to include five patients whose anteroposterior separation had increased, seven in

Table I Alteration in vertical subluxation of odontoid process during study

\begin{tabular}{lrcr}
\hline Increased & 18 & Into foramen magnum \\
Unchanged & 36 & Start & 6 \\
Decreased & 0 & 5 yrs & 10 \\
Total & 54 & & \\
\hline
\end{tabular}

Increase $=$ apparent rise of tip of odontoid process in relation to foramen magnum. whom it was unchanged, and six out of seven in whom it had actually decreased. In ten patients the tip of the odontoid process was actually at or through the foramen magnum compared with six at the start of the study, a situation which is always abnormal and was not found in control subjects. Fig. 4 is an example of a patient whose odontoid process shifted $7 \mathrm{~mm}$ passing through the foramen magnum.

A total of 22 patients had radiological alteration in the upper cervical region during the course of the study shown by shift in an anteroposterior, vertical, or both directions. The relevant features of these patients are shown in Table II, and as might be expected, there is a positive relationship to neck pain, seropositivity, rheumatoid nodules, and the administration of steroids. In particular, seven out of eight patients with mutilating changes in peripheral $x$-rays showed an alteration. 


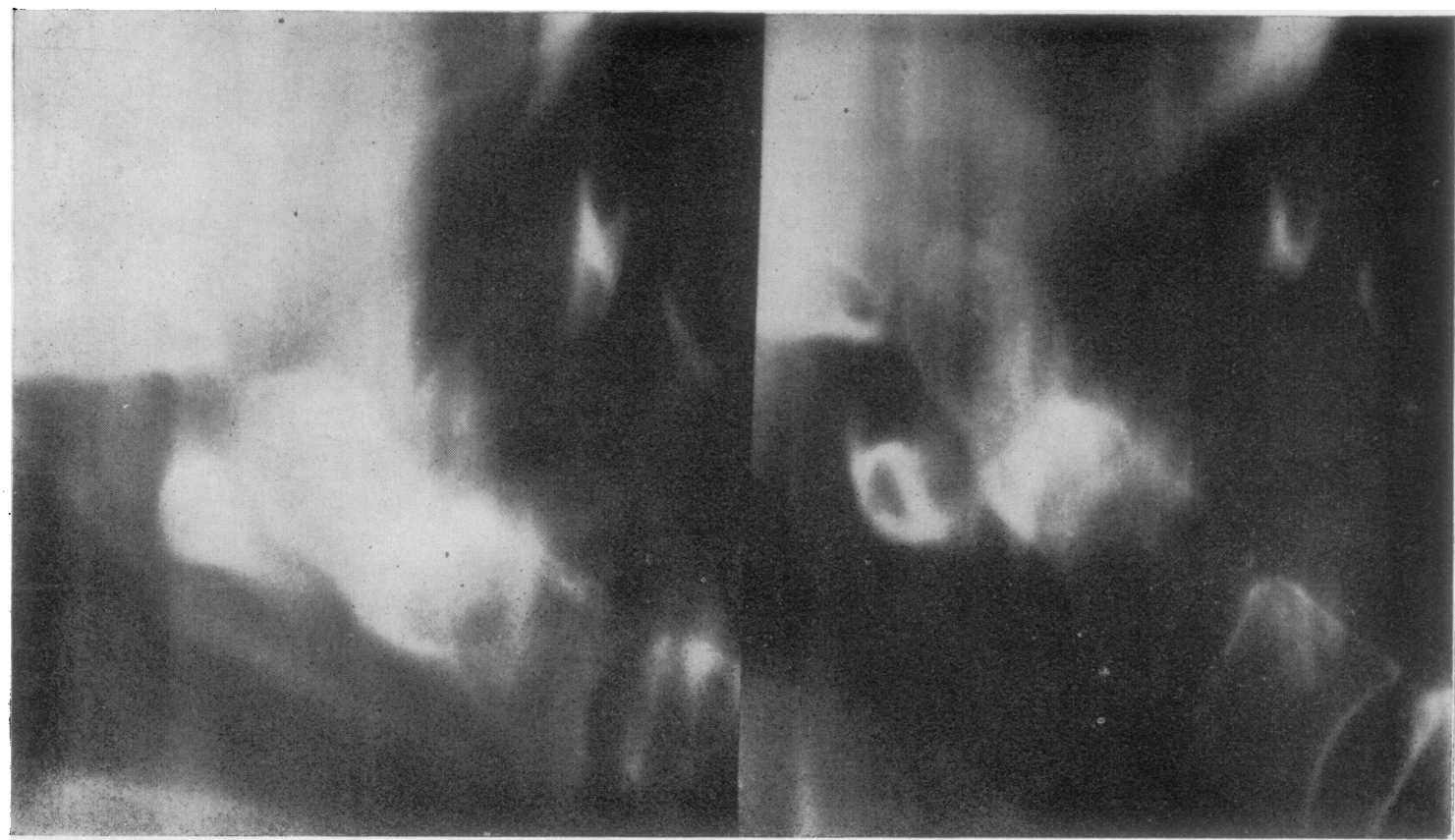

FIG. 4 In this patient there is vertical shift of $7 \mathrm{~mm}-$ from $3 \mathrm{~mm}$ below to $4 \mathrm{~mm}$ above the foramen magnum. At the same time the anteroposterior separation has increased from 3.0 to $6.0 \mathrm{~mm}$

Table II Various features related to increase of anteroposterior and vertical subluxation

\begin{tabular}{|c|c|c|c|c|c|c|c|c|c|c|}
\hline \multirow[t]{2}{*}{ Finding } & \multicolumn{2}{|c|}{ Pain } & \multicolumn{2}{|c|}{ Serology } & \multicolumn{2}{|c|}{ Erosions } & \multicolumn{2}{|c|}{ Nodules } & \multicolumn{2}{|c|}{ Steroids } \\
\hline & + & - & + & - & ++ & + & + & - & + & - \\
\hline $\begin{array}{l}\text { No. of patients } \\
\text { Increased subluxation }\end{array}$ & 32 & 22 & 39 & 15 & 8 & 43 & 13 & 41 & 11 & 43 \\
\hline $\begin{array}{l}\text { no. } \\
\%\end{array}$ & $\begin{array}{l}16 \\
50\end{array}$ & $\begin{array}{r}6 \\
27\end{array}$ & $\begin{array}{l}18 \\
46\end{array}$ & $\begin{array}{r}4 \\
27\end{array}$ & $\begin{array}{r}7 \\
88\end{array}$ & $\begin{array}{l}18 \\
42\end{array}$ & $\begin{array}{r}8 \\
61\end{array}$ & $\begin{array}{l}14 \\
34\end{array}$ & $\begin{array}{r}6 \\
55\end{array}$ & $\begin{array}{l}16 \\
37\end{array}$ \\
\hline
\end{tabular}

\section{NEUROLOGICAL SIGNS}

Many patients had minor and apparently trivial neurological signs and in practice the presence of an extensor plantar response was necessary to provide convincing evidence of long tract damage. At the start of the study, five of the 76 patients had such signs and of these three had anteroposterior subluxation and one vertical subluxation in addition. By the time of follow-up, two of these had died but six more had developed long tract signs, making a total of eleven. Of the nine patients available at follow-up, seven had abnormal anteroposterior separation, five vertical subluxation, only one being normal in both respects (Table III). When the numbers of patients with pyramidal signs are expressed as a proportion of those with a radiological abnormality it can be seen (Table IV) to vary from three out of nineteen with anteroposterior subluxation at the start, to five out of ten with vertical subluxation at follow-up.

\section{Discussion}

The high incidence of atlanto-axial subluxation reported by Conlon, Isdale, and Rose (1966), Mathews (1969), and Meikle and Wilkinson (1971) emphasized the need for further knowledge about the natural history of this condition so that unnecessary treatment for this apparently alarming condition could be avoided and treatment concentrated where needed.

A 6-year follow-up report was published by Isdale and Conlon (1971), who traced 171 of their original 333 patients. The incidence of anteroposterior subluxation in this radiological follow-up more than doubled from 38 to 79 cases. Vertical subluxation was not mentioned and neurological follow-up was incomplete, but no patient showed evidence of gross neurological damage. Smith, Benn, and Sharp (1972), in a large study, examined 962 inpatients of whom 150 had cervical subluxation 
Table III Radiological measurements of all patients with long tract signs

\begin{tabular}{|c|c|c|c|c|c|c|}
\hline & & \multicolumn{5}{|c|}{ Patients with pyramidal signs } \\
\hline & & \multicolumn{2}{|c|}{ Atlanto-axial separation } & \multicolumn{3}{|c|}{ Vertical subluxation } \\
\hline & Before & After & Change & Before & After & Change \\
\hline $\begin{array}{l}\text { Signs at } \\
\text { Case }\end{array}$ & $\begin{array}{l}\text { start } \\
1 \\
2 \\
3 \\
4 \\
5\end{array}$ & $\begin{array}{l}3.0 \\
5 \cdot 0 \\
1 \cdot 5\end{array}$ & $\begin{array}{c}0 \\
0 \\
-0.5\end{array}$ & $\begin{array}{c}-3 \\
-3 \\
-10 \\
0 \\
-1 \cdot 5\end{array}$ & $\begin{array}{r}-10 \\
+2 \\
0\end{array}$ & $\begin{array}{l}0 \\
+2 \\
+1 \cdot 5\end{array}$ \\
\hline $\begin{array}{r}\text { Signs at } \\
\text { Case } \\
\\
1 \\
1\end{array}$ & $\begin{array}{l}2 \cdot 0 \\
3 \cdot 5 \\
4 \cdot 5 \\
6 \cdot 0 \\
3 \cdot 0 \\
4 \cdot 5\end{array}$ & $\begin{array}{l}2.0 \\
4.0 \\
3.5 \\
6.0 \\
6.0 \\
5.0\end{array}$ & $\begin{array}{c}0 \\
0.5 \\
-1 \\
0 \\
+3 \\
+0.5\end{array}$ & $\begin{array}{l}-2 \\
-4 \cdot 5 \\
-3 \\
-6 \\
-3 \\
-2\end{array}$ & $\begin{array}{l}-2 \\
-3 \\
+3 \\
+5^{*} \\
+4 \\
-2\end{array}$ & $\begin{array}{c}0 \\
+1.5 \\
+6 \\
+25^{*} \\
+7 \\
0\end{array}$ \\
\hline $\begin{array}{l}\text { Total } 1 \\
\text { Anterop } \\
\text { Vertical }\end{array}$ & $\begin{array}{l}11 \\
\text { osterior subluxation } \\
\text { subluxation }\end{array}$ & $\begin{array}{l}8 \\
5\end{array}$ & $\begin{array}{l}\text { 4-both } \\
\text { 2-neither }\end{array}$ & & & \\
\hline
\end{tabular}

* Spurious underestimate due to bony destruction.

Table IV Number of patients with subluxation showing long tract signs

\begin{tabular}{ll}
\hline & \multicolumn{1}{c}{ Total } \\
At start & $76<\begin{array}{l}\text { Proportion with long tract signs } \\
3 / 19 \text { with anteroposterior } \\
1 / 6 \text { with vertical }\end{array}$ \\
5-year follow-up $54<\begin{array}{l}7 / 21 \text { with anteroposterior } \\
5 / 10 \text { with vertical }\end{array}$ \\
\hline
\end{tabular}

and twenty evidence of cord damage. Taking the 130 without cord damage at the outset, they discovered 91 patients with anteroposterior atlantoaxial subluxation, nine with vertical subluxation, and 85 with subluxations at other cervical levels. Unfortunately this study only made use of subjective methods for assessing vertical subluxation. Eightyfour of these patients survived an average follow-up time of 7-8 years. Of these, 55 patients started with anteroposterior subluxation and their radiological progress over this period was recorded. They noted that nineteen deteriorated, 28 were unchanged, and eight 'improved or recovered', including five in whom no residual subluxation was visible. Nine of their original 130 patients showed vertical subluxation and this increased to nineteen of those completing the study. Four patients with anteroposterior subluxation developed cord signs and one of these who died tetraplegic also had vertical subluxation. The authors commented that vertical subluxation usually follows anteroposterior subluxation. Although their study differs from that reported in this paper, both in selection and methods of examination of patients, it gives an idea of the likelihood of cord damage developing-and incidentally the uselessness of collars (types not specified) in preventing it. It draws attention to diminishing anteroposterior atlanto-axial subluxation which is attributed to 'spontaneous recovery'.

In the study reported here a $71 \%$ follow-up was achieved. Deterioration in the anteroposterior relationship of atlas to axis was found in nine of the 54 patients (one-sixth) and in the vertical relationship in eighteen patients (one-third)-although by no means all of these patients either became radiologically abnormal or, more important, developed long tract signs. The majority of patients with long tract signs did have radiological abnormalities in the cervical spine but it cannot be claimed that these were always causally related. In most patients the amount of disability did not justify more extensive neuroradiological investigation, although one patient (Case 9, Table III) developed severe and progressive quadriparesis and was found also to have a compressive midcervical subluxation. Foramen magnum decompression and midcervical fusion were performed with considerable relief. It would be useful clinically if the patients at highest risk could be detected, and in this respect it seems that mutilating peripheral joint disease is closely related; by contrast, the absence of pain attributable to the cervical spine by no means excluded radiological deterioration. This study also strongly suggests that the 'spontaneous recovery' referred to above is an illusion and really represents vertical deterioration in a joint already the site of marked anteroposterior 
subluxation. Evidence of this is provided by the finding that six out of seven apparent anteroposterior improvements were accompanied by vertical shift of the odontoid process, and it may well be that more such patients are included in the group whose anteroposterior measurement remained unchanged, i.e. the effects of anteroposterior and vertical shift have 'cancelled out'. One of the six patients with lessening anteroposterior subluxation is illustrated in Fig. 5 where clearly the effect is that of pushing a conical peg into a round hole.

Cervical myelopathy has been reported by Stevens, Cartlidge, Saunders, Appleby, Hall, and Shaw (1971) to occur in two-thirds of patients with atlantoaxial subluxation, but assessment of subjective signs makes comparison between different studies difficult. Certainly this report indicates a similar risk (even using stricter neurological criteria) in anteroposterior atlanto-axial subluxation and an even higher risk in vertical subluxation-whose mechanism, possible severe sequelae, and management were reported in three cases by Swinson, Hamilton, Mathews, and Yates (1972).

The variable and not universally poor prognosis of patients with atlanto-axial subluxation makes it unnecessary and unkind to subject all to uncomfortable and restricting collars. My view is that these patients should be kept under review, the neck immobilized as best possible if signs of cord damage develop, and surgery as described by Crellin, Maccabe, and Hamilton (1970) be undertaken if control is not achieved.

\section{Summary}

A 5-year follow-up study of the clinical and radiological changes relating to the atlanto-axial joint in a group of 76 rheumatoid patients is discussed. Of the 54 patients completing the 5-year study, one-third of those with anteroposterior and half of those with vertical subluxation had long tract signs, often arising in patients with severe disease. A policy for avoiding unnecessarily restrictive treatment of the remainder is suggested. An original explanation for apparent improvement is anteroposterior subluxation is advanced.

I am grateful to Dr. J. W. Pierce and the Department of Radiology for their co-operation, and Mr. T. Brandon and the Photographic Department for the illustrations.

\section{DISCUSSION}

DR. D. R. SWINSON (King's) There is some anecdotal evidence and you presented some more evidence to suggest that patients with vertical atlanto-axial subluxation fare badly compared with ordinary forward subluxation of the atlas. Have you any more figures to confirm or refute this impression?

DR. MATHEWS I hope these are the sort of figures you meant (Table IV). Remember there were 76 patients at the 0 beginning of the study and five of these had pyramidal: signs. There were nineteen with anteroposterior subluxation and three of those had pyramidal signs. There were six with vertical subluxation and one of the six had pyramidal signs. By the time you get to the end of the
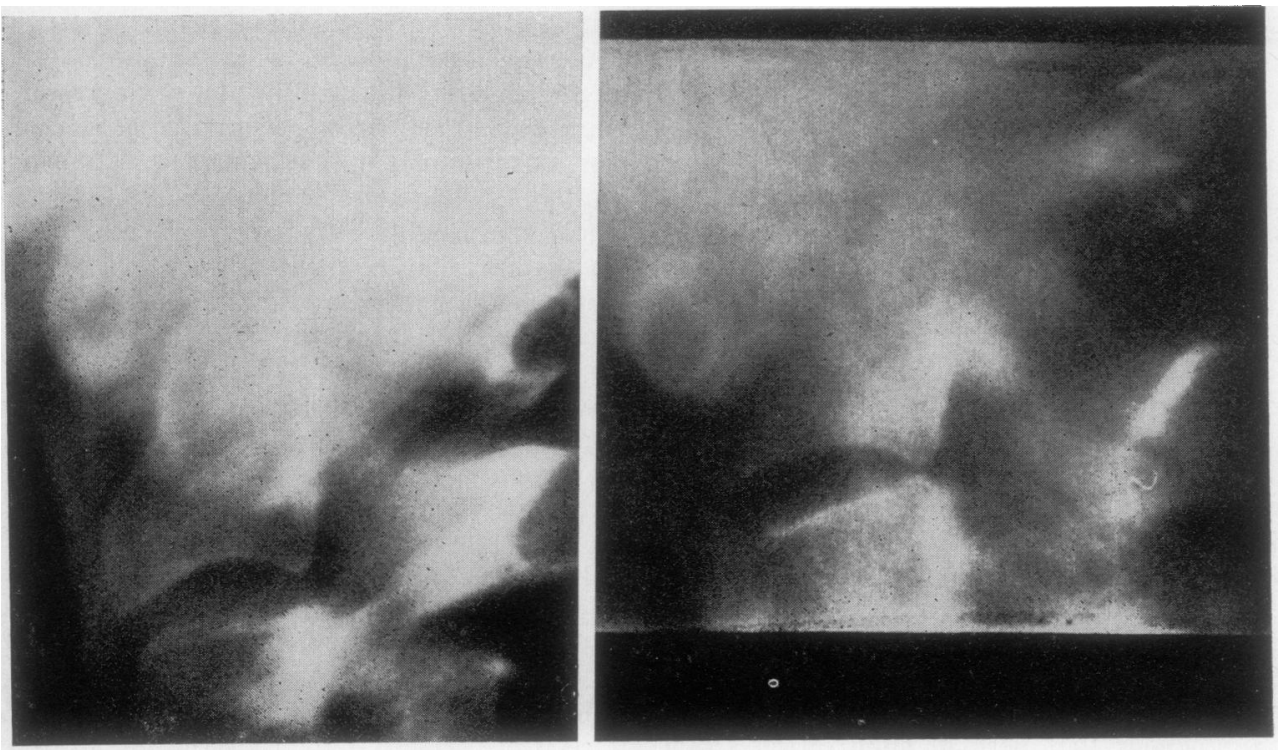

FIG. 5 This pair of $x$-rays demonstrates that the lessening of anteroposterior separation is due to dramatic deterioration of vertical subluxation (peg-in-hole effect) 
study the situation really looks quite a bit worse in patients with radiological abnormalities. We have nine with pyramidal signs out of 54 , that is one-sixth. Five out of ten with vertical and seven out of 21 with anteroposterior subluxation have extensor plantars; so a third of the anteroposterior and half of the vertical subluxers have extensor plantars.

DR. M. THOMPSON (Newcastle) The distance from the posterior aspect of the odontoid to the anterior aspect of the vertebral arch seems to be a very important measurement. I think you have performed a great service in considering these correlations between anteroposterior subluxation and vertical movement. Have you any information on the spinal canal depth?

DR. MATHEWS I did publish in the original survey (Mathews, 1969) the vital statistics of the five patients who had long tract signs and I didn't find any relationship except possibly in one patient whose canal depth posterior to the odontoid process was $19 \mathrm{~mm}$. Thus I didn't find any correlation between the remaining space for the spinal cord and the development of long tract signs.

DR. D. R. HENDERSON (Guy's) When we looked at a group of patients with vertical subluxation in Bath we found that there was a high incidence of severe subluxation in the lower part of the cervical spine and that where we found severe and definite pyramidal signs these seemed to be almost certainly due to the lower cervical subluxation. We also found cranial nerve palsies and I would like to ask if you found these as well and what the lower part of the cervical spine in these patients looked like on $x$-ray?

DR. MATHEWS Thank you for giving me the chance to point out some of the defects in this study. I cannot really conclude that any of these patients developed their neurological signs because of the $x$-ray changes. Only a few of them had progressive neurological signs which would demand thorough neurological examination including cervical myelograms, but I do agree that I should really have $x$-rayed the whole length of the cervical spine and would do so if starting again. I did a limited neurological examination and it seemed that the most relevant signs might be the absence of a corneal reflex. I examined the corneal reflex in every patient and I didn't find that it was absent very often; it certainly did not relate to any of the $x$-ray changes.

DR. K. N. LLOYD (Cardiff) In view of the figures that you have just shown, the inference is that the longer any form of subluxation has been present, the more likely there are to be long tract signs. Further, how were you certain that these patients were $x$-rayed in the same degree of flexion after this 5-year interval?

DR. MATHEWS In the original survey I took great care about this. I checked reproducibility by $x$-raying twenty of the patients on a second occasion and, except in two patients in whom the disease was obviously getting worse, I found that the measured gap didn't alter by more than $0.5 \mathrm{~mm}$ between one $x$-ray examination and another. I always put the patient's cervical spine into the maximum amount of active flexion until pain or stiffness brought the range to an end. I think it is fortunate that this turns out to give reproducibility of $0.5 \mathrm{~mm}$. Now when it comes to the 5-year follow-up study, I found that owing to the appearance of erosions the anatomy was often quite altered so that I could not make the direct tracing comparison which I would have liked, but I could still put the $x$-rays side by side and measure gaps of a mm, which were incidentally visually obvious. If they were less than a mm I haven't included them as changes in this study.

\section{References}

Conlon, P. W., Isdale, I. C., AND Rose, B. S. (1966) Ann. rheum. Dis., 25, 120 (Rheurnatoid arthritis of the cervical spine)

Crellin, R. Q., Maccabe, J. J., ANd Hamilton, E. B. D. (1970) J. Bone Jt Surg., 52B, 244 (Severe subluxation of the cervical spine in rheumatoid arthritis)

Isdale, I. C., AND Conlon, P. W. (1971) Ann. rheum. Dis., 30, 387 (Atlanto-axial subluxation: a six year follow-up report)

MATHEWs, J. A. (1969) Ibid., 28, 260 (Atlanto-axial subluxation in rheumatoid arthritis)

MeIKLE, J. A. K., AND Wilkinson, M. (1971) Ibid., 30, 154 (Rheumatoid involvement of the cervical spine: radiological assessment)

Smith, P. H., BenN, R. T., AND ShaRP, J. (1972) Ibid., 31, 431 (Natural history of rheumatoid cervical luxations)

Stevens, J. C., Cartlidge, N. E. F., Saunders, M., Appleby, A., Hall, M., and Shaw, D. A. (1971) Quart. J. Med., 40, 391 (Atlanto-axial subluxation and cervical myelopathy in rheumatoid arthritis)

Swinson, D. R., Hamilton, E. B. D., Mathews, J. A., AND Yates, D. A. H. (1972) Ann. rheum. Dis., 31, 359 (Vertical subluxation of the axis in rheumatoid arthritis) 